\title{
CADERNO DE IMAGENS: A INDUMENTÁRIA EM ADAPTAÇÕES DE OBRAS DE MACHADO DE ASSIS
}

\section{MARIANA MILLECCO}

Universidade Federal do Rio de Janeiro

Rio de Janeiro, Rio de Janeiro, Brasil

\author{
ANA CLÁUDIA SURIANI DA SILVA \\ University College London \\ Londres, Reino Unido,
}

Resumo: Este caderno de imagens faz um passeio pela obra do escritor através dos olhos de alguns diretores e suas equipes de produção, conjugando citações retiradas dos textos e comentários sobre a indumentária das figuras. Faz sentido essa conjunção, uma vez que o escritor criticou e comentou os costumes sociais e as modas do seu tempo, assim como figurinos e cenários de peças teatrais. Ele também insere nos seus textos várias passagens descritivas a respeito da roupa e características físicas das personagens, misturando a poesia da matéria e as cores da psicologia humana, numa construção literária ímpar.

Palavras-chave: Machado de Assis; indumentária; adaptações para cinema e TV

\section{PHOTO ALBUM: THE CLOTHING}

IN ADAPTATIONS OF MACHADO DE ASSIS'S WORKS

Abstract: This scrapbook of images examines the author's work through the eyes of directors and production teams, collecting citations taken from his texts and adding comments about the clothing worn by characters. This convergence makes sense, since the author fictionalized, criticized and discussed the social attire and fashion of his time, as well as the costumes and sets of plays. He also dedicates various passages of his texts to descriptions of clothing and the physical features of character, mixing the poetry of the subject and the colors of human psychology to create a unique literary construction.

Keywords: Machado de Assis; clothing; adaptations into film and television 
Figura 1 Confissões de uma viúva moça, 1975

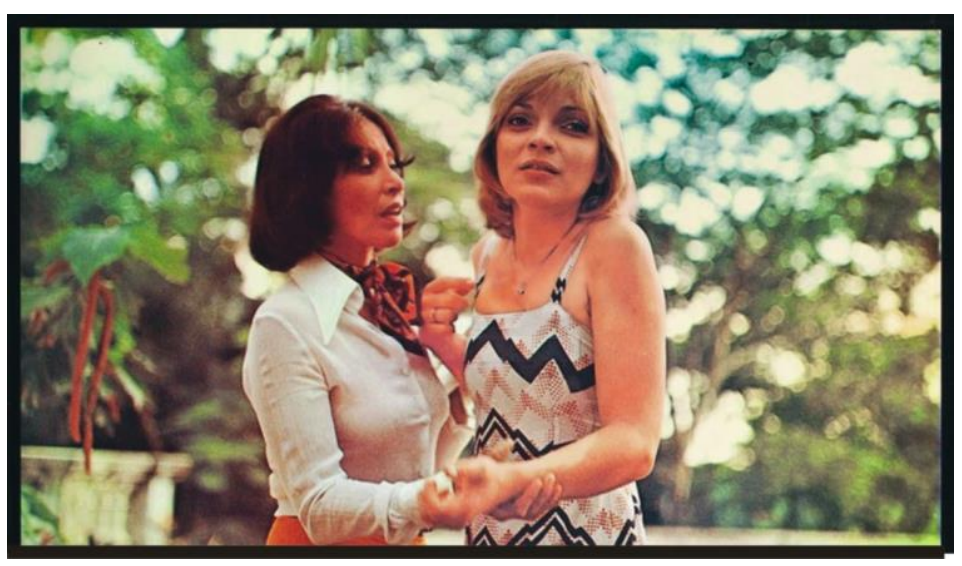

Somos todas vaidosas da nossa beleza e desejamos que o mundo inteiro nos admire. É por isso que muitas vezes temos a indiscrição de admirar a corte mais ou menos arriscada de um homem. Há, porém, uma maneira de fazê-la que nos irrita e nos assusta; irrita-nos por impertinente, assusta-nos por perigosa. ${ }^{1}$

Apesar de as obras de Machado de Assis se inscreverem temporalmente no século XIX, algumas de suas transposições para os meios audiovisuais se deram de forma livre no que diz respeito à ambientação de época. $O$ filme de Adnor Pitanga (1975) se encontra nesse caso. Como vemos na imagem, desde os cortes de cabelo ao figurino dos personagens identificamos a moda da década de 1970. Chamam a atenção a camisaria de modelagem justa e gola pontuda, o lenço amarrado no pescoço e a elegância na forma de um padrão de estamparia gráfico, déco, da roupa de Sandra Barsotti. Nessa época eram comuns os cortes de cabelo feminino e masculino parecidos, revelando-nos que a moda seguia o caminhar da cultura hippie na direção de uma sociedade mais igualitária. Se nos direitos sociais isso ainda é reivindicado, com alguns avanços significativos, mas ainda em processo de conquistas, ao menos na moda, principalmente com o surgimento de artistas como David Bowie (Movimento Glam-rock, Glitter...),

1 Todas as citações da obra de Machado de Assis foram retiradas de http://machadodeassis.net/hiperTx_romances/index.asp. Acesso em: 23 dez. 2016. 
homens e mulheres flexibilizaram suas fronteiras estéticas, ao compartilharem o uso das cores. O conceito de masculidade foi revisto ao ser admitido como possuidor de fronteiras mais fluidas.

Filme baseado no conto homônimo publicado originalmente no Jornal das Famílias, de abril a junho de 1865, assinado por J., e posteriormente escolhido para figurar na primeira coletânea de contos do escritor, Contos fluminenses, 1870.

Direção e roteiro: Adnor Pitanga;

Fotógrafo não identificado;

Elenco: Sandra Barsotti, José Wilker, Celso Faria, Myriam Pérsia;

Disponível em: http://astrosemrevista.blogspot.co.uk/2015/04/sandrabarsotti-gata-de-grandes-olhos.html. Acesso em: 1 fev. 2017. 


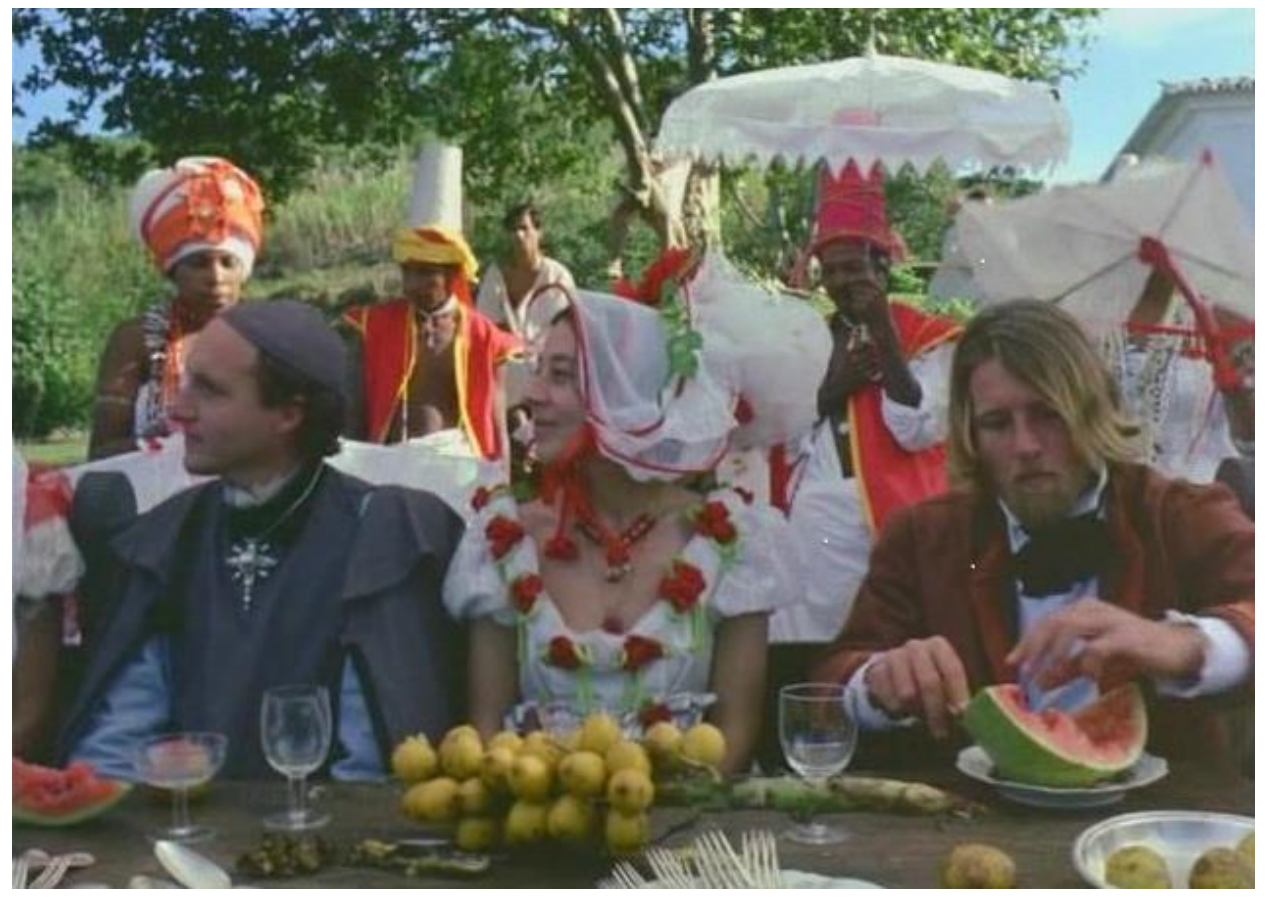

D. Evarista, contentíssima com a glória do marido, vestira-se luxuosamente, cobriu-se de joias, flores e sedas. Ela foi uma verdadeira rainha naqueles dias memoráveis; ninguém deixou de ir visitá-la duas e três vezes, apesar dos costumes caseiros e recatados do século.

A figura central feminina usa um chapéu com uma modelagem que lembra o bonnet, e aparentemente o vestido fica entre as épocas neoclássica e romântica do início do século XIX, cintura império. Do começo do século até a década de 1820, a base do vestido se ampliou ganhando mais volume e saindo da silhueta tipo coluna. A imagem traz adereços de cabeça, turbantes e chapéus extremamente volumosos e altos, que estão de acordo com a época romântica de cartolas de copa alta, penteados exuberantes etc. Este filme possui uma profusão de referências, assim como subverte as representações do conto "O alienista" no qual se baseia, um espírito totalmente livre e de acordo com o da década de 1970 na qual foi realizado.

Filme baseado no conto "O alienista", publicado originalmente em $A$ Estação de outubro de 1881 a março de 1882, assinado por Machado de Assis, e 
posteriormente escolhido para figurar na coletânea de contos Papéis avulsos, 1882.

Direção e roteiro: Nelson Pereira dos Santos;

Elenco: Nildo Parente, Isabel Ribeiro, Arduíno Colasanti, Irene Stefânia, Leila Diniz;

Disponível em: http://rarefilm.net/wp-content/uploads/2016/03/AzylloMuito-Louco-Nelson-Pereira-dos-Santos-1970-2.jpg. Acesso em: 1 fev. 2017. 


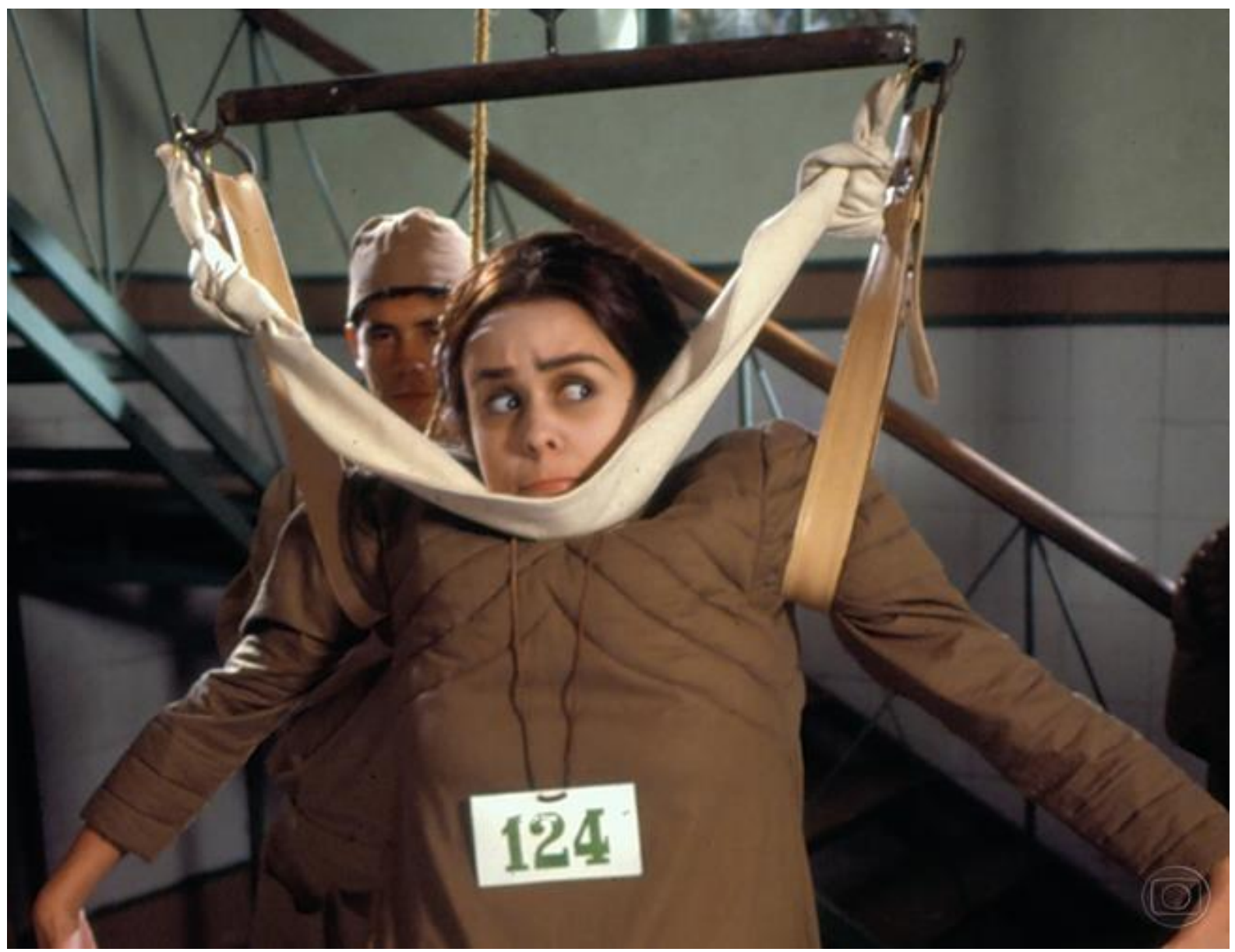

Alta noite, seria hora e meia, acordo e não a vejo; levanto-me, vou ao quarto de vestir, acho-a diante dos dous colares, ensaiando-os ao espelho, ora um ora outro. Era evidente a demência: recolhi-a logo.

A roupa utilizada pelos pacientes do Dr. Bacamarte é uma mistura fantasiosa de referências icônicas como o camisolão de dormir do século XIX, a camisola de internos em hospitais e a camisa de força, e o aspecto metalassado de revestimento dos quartos de segurança, acolchoados. Todos esses elementos parecem ter sido misturados na hora da criação dessa peça de figurino nesta transposição do conto "O alienista" para o caso especial homônimo, que se refere visualmente ao periódico histórico em que se inscreve. 
Minissérie baseada no homônimo publicado originalmente em $A$ Estação de outubro de 1881 a março de 1882, assinado por Machado de Assis, e posteriormente escolhido para figurar na coletânea de contos Papéis avulsos, 1882.

Elenco: Marco Nanini, Giulia Gam, Milton Gonçalves, Cláudio Correa e Castro, Antônio Calloni, Marisa Orth, Sérgio Mamberti, e Luís Fernando Guimarães;

Disponível em: http://memoriaglobo.globo.com/perfis/talentos/giuliagam.htm. Acesso em: 1 fev. 2017. 


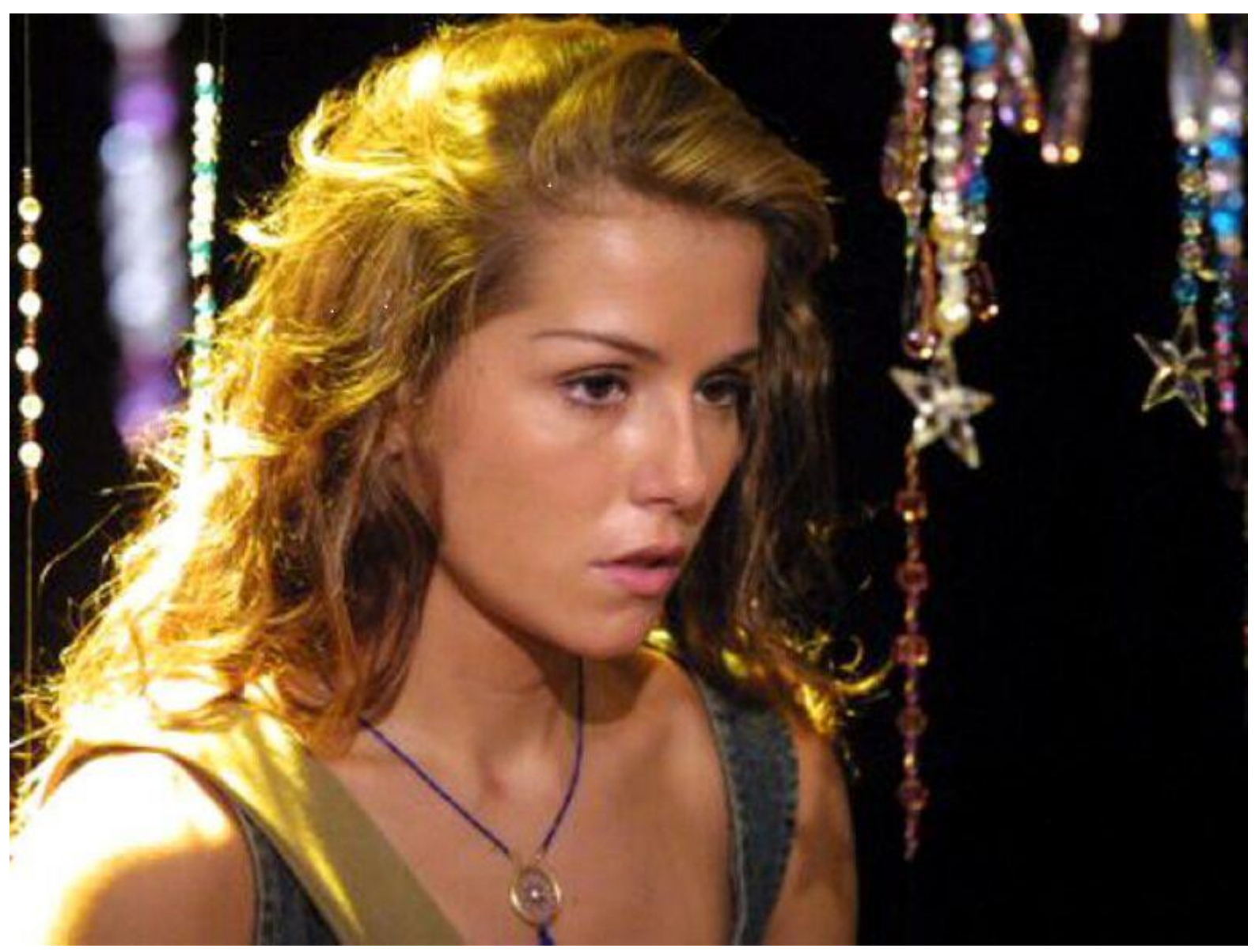

A verdade é que gostava de passar as horas ao lado dela, era a sua enfermeira moral, quase uma irmã, mas principalmente era mulher e bonita. Odor di femmina: eis o que ele aspirava nela, e em volta dela, para incorporá-lo em si próprio.

O jeans (que vemos na alça da peça usada por Deborah Secco) consolida no final do século XX seu lugar como peça e material mais democrático de toda a história. As calças adquirem todos os modelos, cores, lavagens, segundo o desejo de quem as usa: vão da padaria à boate, do trabalho ao domingo no parque. Como material, ultrapassa as calças e se instala nas saias, shorts, na camisaria, nos acessórios, mostrando-se um tecido absolutamente versátil e não exclusivo a 
uma determinada classe social. Atende a toda e a qualquer demanda, tornandose muitas vezes peça desejo de marcas e estilistas.

Filme baseado no conto homônimo, publicado originalmente na Gazeta de Notícias, em 28 de novembro de 1884, assinado por Machado de Assis, e posteriormente escolhido para figurar na coletânea de contos Várias histórias, 1891.

Direção: Wagner de Assis e Pablo Uranga;

Elenco: Deborah Secco, Luigi Baricelli, Sívia Pfeifer, Christiane Alves, Giovanna Antonelli, Mel Lisboa, Sílvio Guindane;

Disponível em: http://www.jorgetadeu.com.br/cc_acartomante.htm. Acesso em: 1 fev. 2017. 


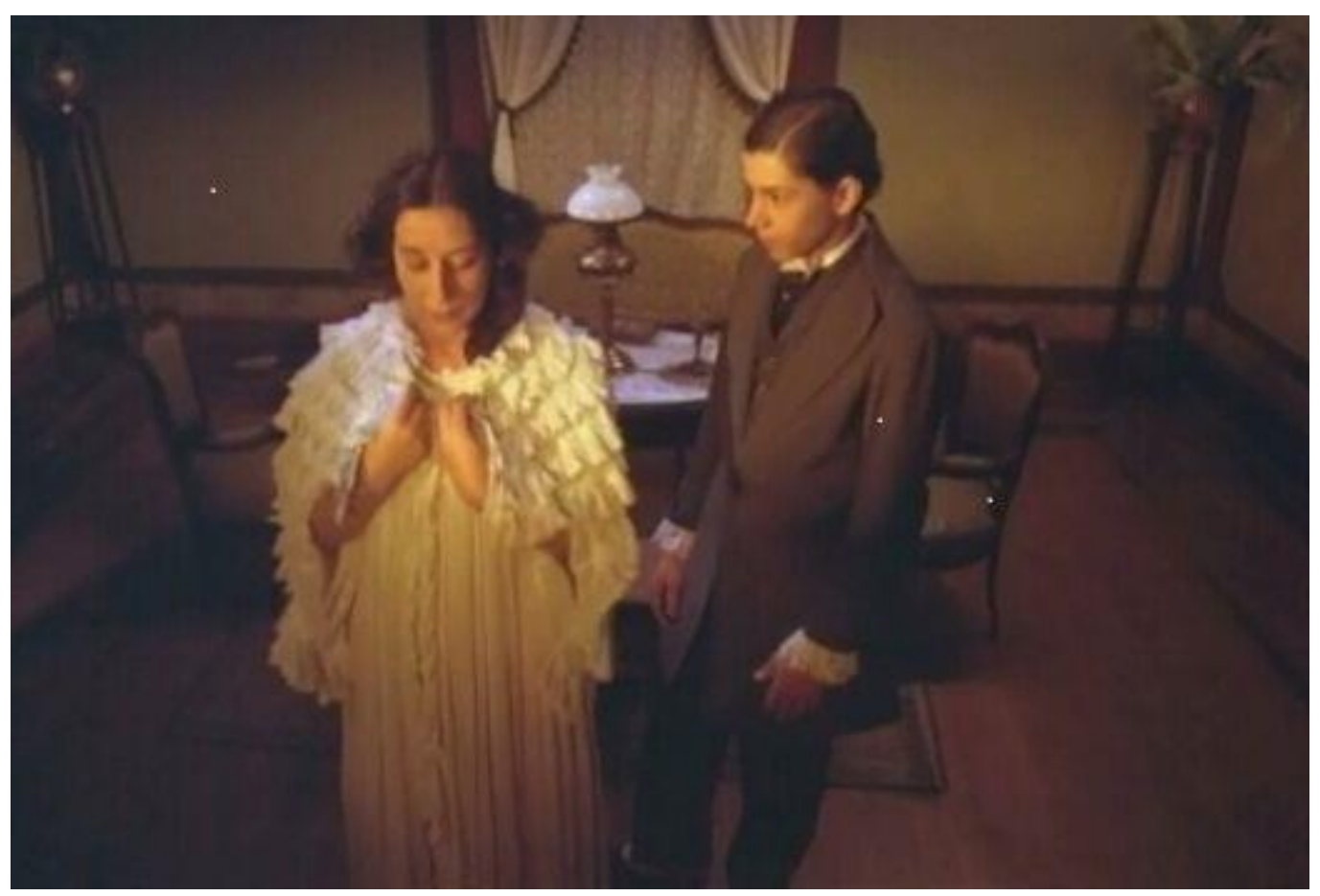

Conceição entrou na sala, arrastando as chinelinhas da alcova. Vestia um roupão branco, mal apanhado na cintura. Sendo magra, tinha um ar de visão romântica, não disparatada com o meu livro de aventuras.

Personagem feminina trajando a camisola de dormir e penhoar de camadas de tecido em babados. Já a personagem masculina traja a moda do século XIX: terno, camisa branca com gola levantada e lenço no pescoço com alfinete, ao estilo dândi.

Filme baseado no conto homônimo, publicado originalmente em $A$ Semana, em 12 de maio de 1894, assinado por Machado de Assis, e posteriormente escolhido para figurar na coletânea de contos Páginas recolhidas, 1899.

Direção e roteiro: Nelson Pereira dos Santos;

Elenco: Isabel Ribeiro, Nildo Parente, Olney São Paulo;

Disponível em: http://cinediario.blogspot.co.uk/2012/03/missa-do-galocurioso-como-nelson.html. Acesso em: 1 fev. 2017. 


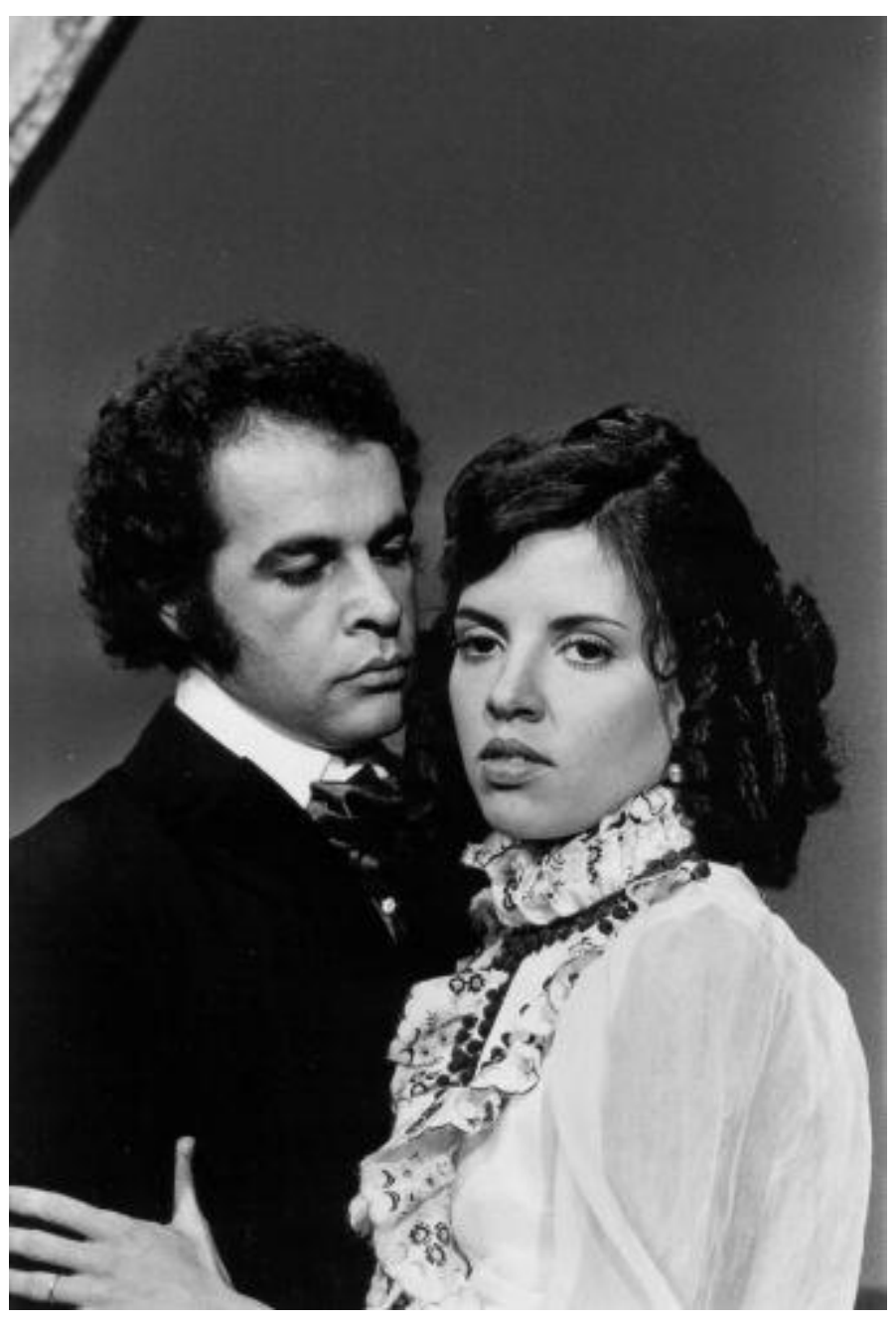

Goethe escreveu um dia que a linha vertical é a lei da inteligência humana. Pode dizer-se, do mesmo modo, que a linha curva é a lei da graça feminil. Mendonça o sentiu, contemplando o busto de Helena e a casta ondulação da espádua e do seio, cobertos pela cassa fina do vestido. ${ }^{2}$

Mais uma figura dândi masculina em contraposição à figura feminina vestida à moda da segunda metade do século XIX. O romance fora publicado na década de 1870, quando o volume da saia vitoriana é paulatinamente transferido,

${ }^{2} \mathrm{O}$ ator que aparece na foto, Osmar Prado, fazia o papel de Estácio, não de Mendonça. 
deixando a silhueta da parte de baixo aos poucos reta na frente e volumosa na parte de trás. A parte superior ganha o volume de babados e outros adereçamentos, e o corpo feminino passa a ser totalmente coberto durante o dia, reservados os decotes para os bailes e a vida noturna. Esta moda aos poucos resulta na silhueta em "S" da Belle Époque que irá atravessar o final do século XIX e o início do XX.

Novela baseada no romance homônimo, publicado originalmente em folhetins em $O$ Globo, de 6 de agosto a 11 de setembro de 1876, e logo em seguida em livro, ainda no ano de 1876.

Direção: Herval Rossano;

Adaptação: Gilberto Braga;

Elenco: Lúcia Alves, Osmar Prado, Ida Gomes, Rogério Fróes, Ruth de Sousa, Sidney Marques, Regina Vianna, Gilberto Salvio, Ângela Valério, José Augusto Branco;

Disponível em: http://televisao.uol.com.br/album/gilberto-bragaobras_album.htm. Acesso em: 1 fev. 2017. 


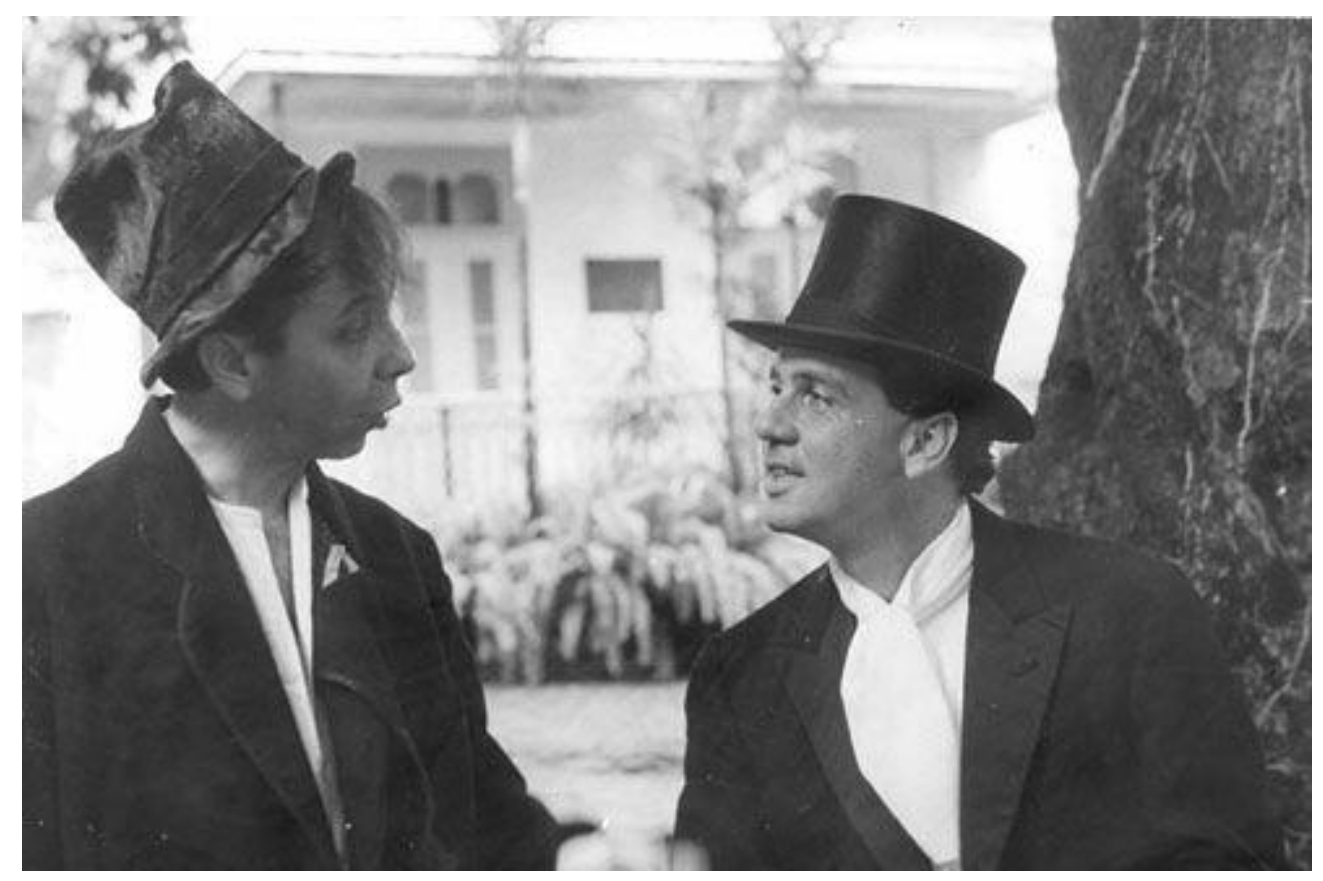

Leitor obtuso, isso prova que nunca entraste no cérebro de um chapeleiro. Um chapeleiro passa por uma loja de chapéus; é a loja de um rival, que a abriu há dous anos; tinha então duas portas, hoje tem quatro; promete ter seis e oito. Nas vidraças ostentam-se os chapéus do rival; pelas portas entram os fregueses do rival; o chapeleiro compara aquela loja com a sua, que é mais antiga e tem só duas portas, e aqueles chapéus com os seus, menos buscados, ainda que de igual preço.

A cartola era um chapéu de aba estreita, copa alta e no formato cilíndrico. Normalmente em cores neutras e de material brilhante, acompanhava o fraque e a casaca tanto de dia quanto à noite. Inventado no século XVIII, esse acessório vem a marcar notavelmente o século seguinte, em que viveu Machado de Assis, e esta produção foi mais uma a ambientar-se no século originário da sua escrita.

Filme baseado no romance Memórias póstumas de Brás Cubas, publicado originalmente na Revista Brasileira, de 15 de março a 15 de dezembro de 1880, e no ano seguinte em livro.

Direção: Julio Bressane; 
Adaptação: Antonio Medina e Julio Bressane;

Elenco: Luiz Fernando Guimarães, Renato Borghi, Bia Nunes, Regina Casé; Disponível em:

http://www.pmf.sc.gov.br/mobile/index.php?pagina=notpagina\&noti=655

3. Acesso em: 1 fev. 2017. 


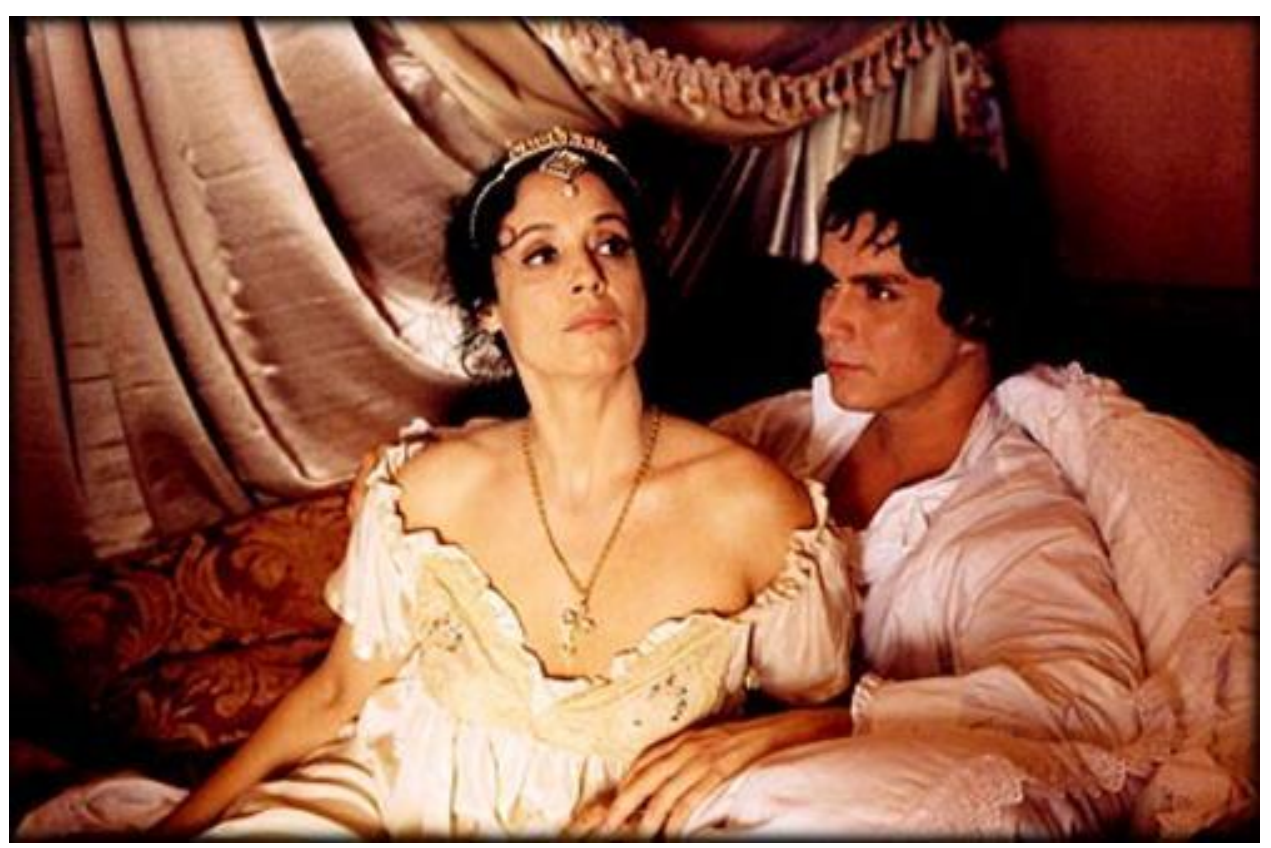

[...] Marcela amou-me durante quinze meses e onze contos de réis; nada menos. Meu pai, logo que teve aragem dos onze contos, sobressaltou-se deveras; achou que o caso excedia as raias de um capricho juvenil.

A personagem em destaque nesta imagem, Marcela, se apresenta com uma camisola, roupa íntima de dormir. O detalhe do busto de aplicação de renda faz com que na frente a marcação lembre o corte da cintura clássica (talvez uma referência à origem do termo "messalina", e à moda império do início do século XIX): o decote de ombro a ombro com o tecido franzido, a corrente no pescoço e o adorno de cabeça. Marcela tem uma influência latina, principalmente da indumentária espanhola. Todo esse conceito referencial merece, é claro, um estudo mais aprofundado de intenções da figurinista. O que imprime é uma imagem lânguida e sedutora, independente da origem dos códigos visuais buscados.

Filme baseado no romance Memórias póstumas de Brás Cubas, publicado originalmente em folhetins na Revista Brasileira, de 15 de março a 15 de dezembro de 1880, e no ano seguinte em livro. 
Direção: André Klotzel;

Adaptação: José Roberto Torero;

Elenco: Reginaldo Faria, Sônia Braga, Walmor Chagas, Stepan Nercessian, Petrônio Gontijo, Viétia Rocha;

Disponível em:

http://salalatinadecinema.blogspot.co.uk/2013/04/memorias-postumas-

de-bras-cubas-brasil.html. Acesso em: 1 fev. 2017. 


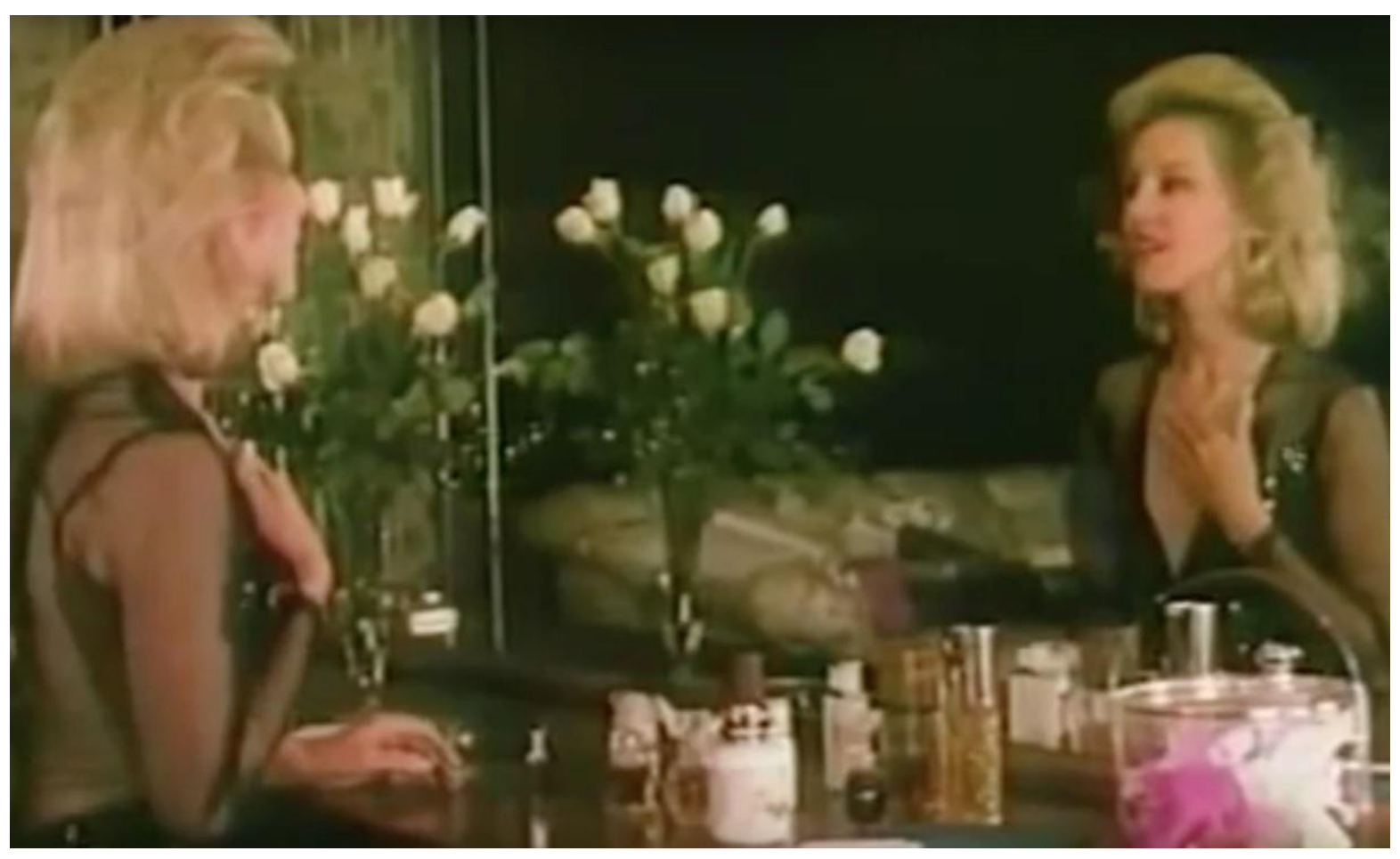

Ia muita vez ao teatro sem gostar dele, e a bailes, em que se divertia um pouco - mas ia menos por si que para aparecer com os olhos da mulher, os olhos e os seios. Tinha essa vaidade singular; decotava a mulher sempre que podia, e até onde não podia, para mostrar aos outros as suas venturas particulares. Era assim um rei Candaules, mais restrito por um lado, e, por outro, mais público.

A imagem da mulher da década de 1980, vestida para o sucesso. Vestido justo unindo três tendências da moda da época: o decote profundo, o brilho e a "segunda pele". Cabelos escovados para trás e armados deixando em evidência a maquiagem marcante dos lábios. A década de 1980 viu surgir em resposta ao movimento hippie os chamados yuppies (young urban professional): jovens profissionais que tinham como lema "work hard play hard" e quanto mais ganhavam mais gastavam. O importante era ser e parecer bem-sucedido.

Filme baseado no romance homônimo, publicado originalmente em 
folhetins em A Estação e em livro ainda no ano de 1891.

Direção e adaptação: Roberto Santos;

Fotógrafo: Airton de Magalhães;

Elenco: Helber Rangel, Brigitte Broder, Fulvio Stefanini.

Disponível em: https://wn.com/resenha_47_quincas_borba. Acesso em: 1 fev. 2017. 


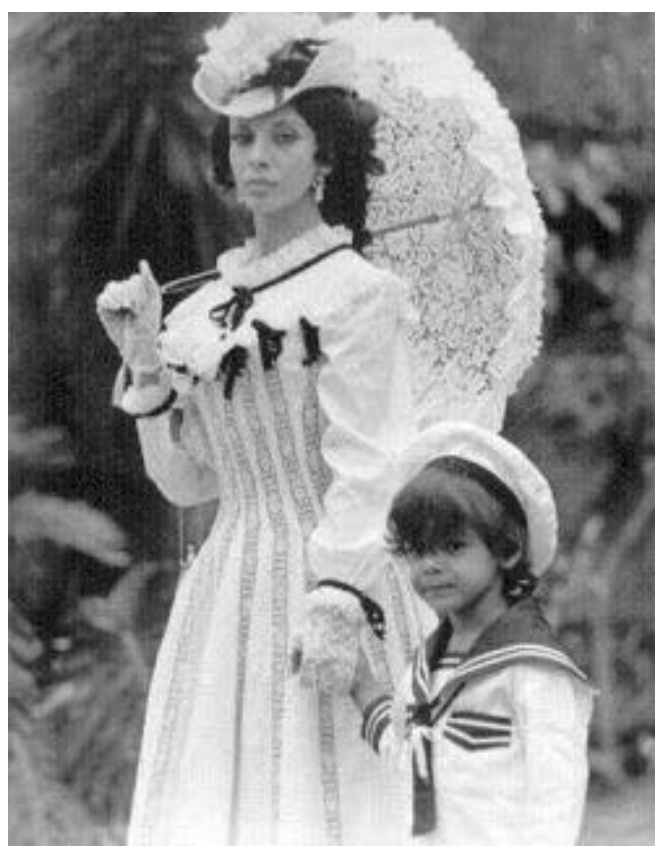

Ezequiel, quando começou o capítulo anterior, não era ainda gerado; quando acabou era cristão e católico. Este outro é destinado a fazer chegar o meu Ezequiel aos cinco anos, um rapagão bonito, com os seus olhos claros, já inquietos, como se quisessem namorar todas as moças da vizinhança, ou quase todas.

Como consequência de uma elitização do uso da calça comprida, até então uniforme dos trabalhadores tanto urbanos quanto do campo, e do uso dos uniformes militares e da marinha como trajes de gala e cerimônia, vemos a libertação do menino do traje tradicional, do vestido comprido fora de moda e das calças justas até os joelhos. Adota-se assim a calça na roupa infantil masculina. Na Inglaterra da metade do século XIX, vestir as crianças de marinheiro havia se tornado moda devido às aspirações dos pais quanto à carreira dos filhos, já que desde o início do século a marinha britânica era considerada uma das mais prestigiosas no mundo - sem contar a aparição em 1850 do então futuro príncipe de Gales, Eduardo VII, usando o traje de calças brancas e casaco de gola quadrada adornado com galões, a bordo do iate real, Victoria \& Albert. 
Filme baseado no romance Dom Casmurro, 1899.

Direção, roteiro e produção: Paulo César Saraceni;

Adaptação: Lygia Fagundes Telles, Paulo Emílio Salles Gomes e Paulo César Saraceni;

Elenco: Othon Bastos, Raul Cortez, Marília Carneiro;

Disponível em: http://entrefilmes.blogspot.co.uk/2008/11/capitu-domcasmurro-machado-de-assis.html. Acesso em: 1 fev. 2017. 
Figura 11 Capitu, 2008

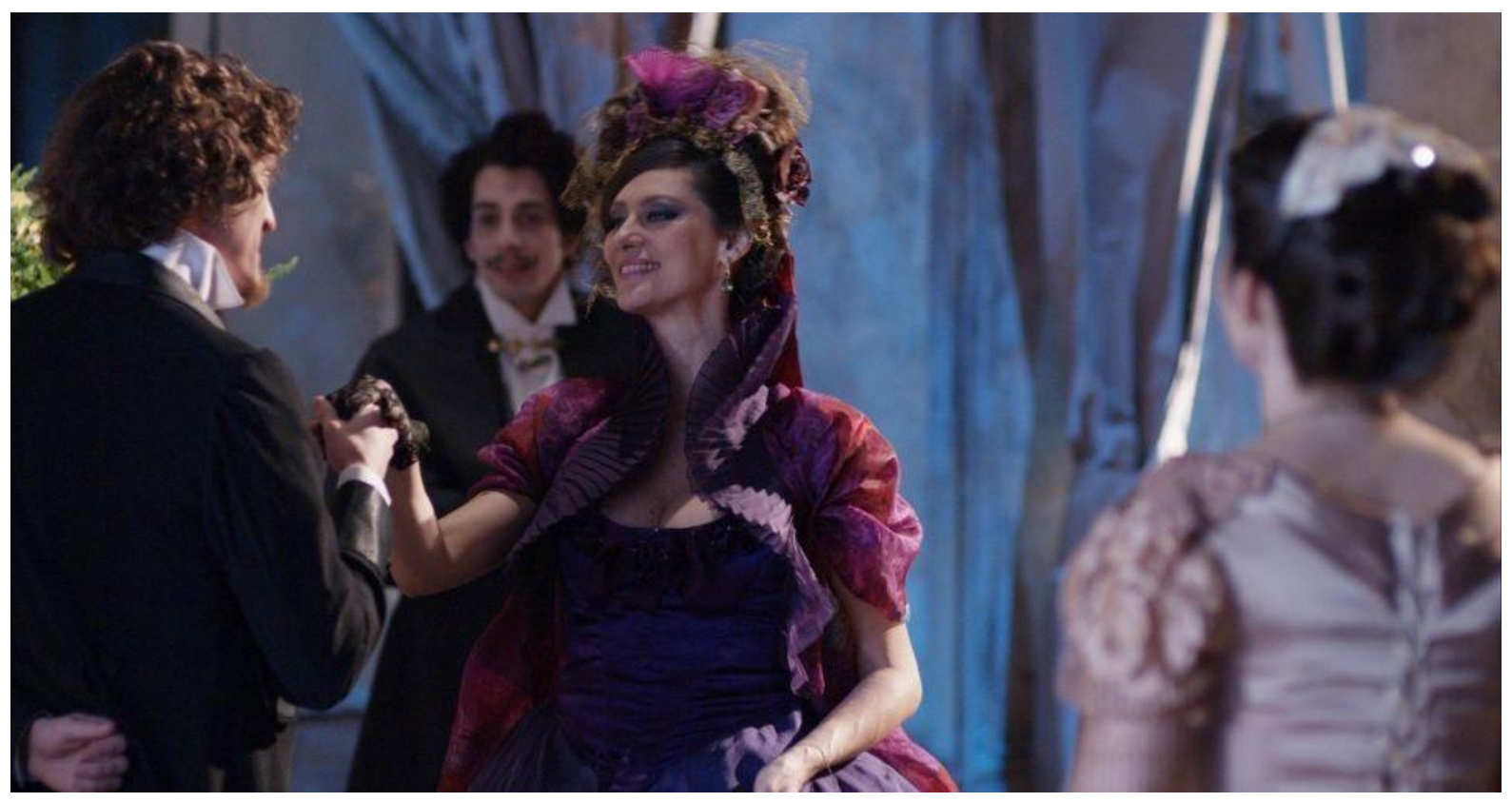

Eram belos, e na primeira noite que os levou nus a um baile, não creio que houvesse iguais na cidade, nem os seus, leitora, que eram então de menina, se eram nascidos, mas provavelmente estariam ainda no mármore, donde vieram, ou nas mãos do divino escultor. Eram os mais belos da noite, a ponto que me encheram de desvanecimento. Conversava mal com as outras pessoas, só para vê-los, por mais que eles se entrelaçassem aos das casacas alheias.

Capitu traz os braços desnudos como é permitido na vida noturna da Belle Époque. O vestido é composto de um corset e saia ampla, correspondendo à moda da década de 1850. Uma sobreposição com gola plissada na forma de uma capinha e as luvas curtas de renda completam e fazem desta imagem feminina um passeio pela moda do século XIX.

Minissérie baseada no romance Dom Casmurro, 1899.

Diretor: Luiz Fernando Carvalho;

Adaptação: Euclydes Marinho com a colaboração de Daniel Piza, Luís Alberto de Abreu e Edna Palatnik;

Elenco: Maria Fernanda Cândido, Michel Melamed, Eliane Giardini, César 


\section{Cardadeiro, Letícia Persiles, Pierre Baitell;}

Disponível em:

http://televisao.uol.com.br/album/Especiais_fim_de_ano_album.htm\#fotoNav= 42. Acesso em: 1 fev. 2017. 


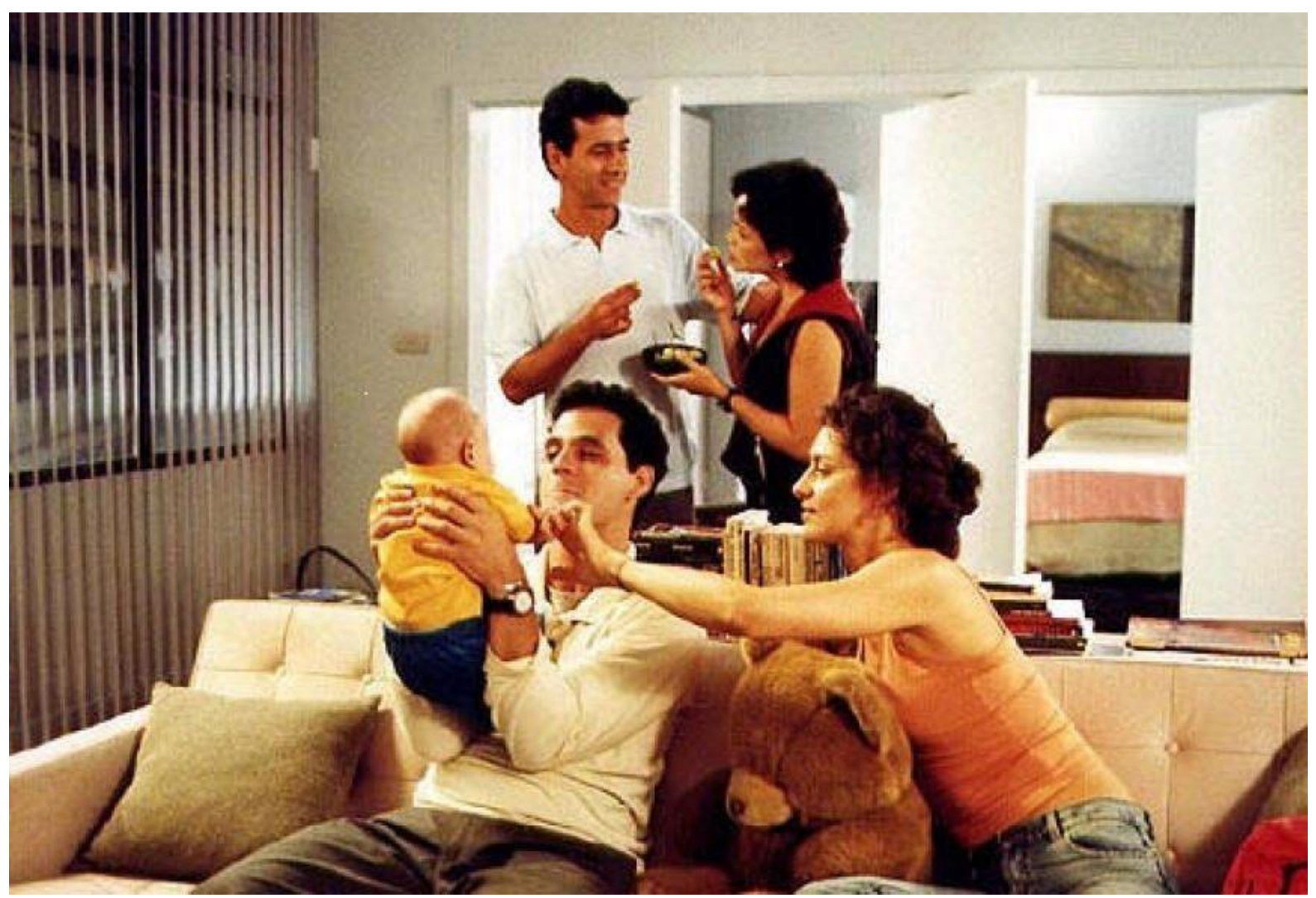

Demais, as nossas relações de família estavam previamente feitas; Sancha e Capitu continuavam depois de casadas a amizade da escola, Escobar e eu, a do seminário. Eles moravam em Andaraí, aonde queriam que fôssemos muitas vezes, e, não podendo ser tantas como desejávamos, íamos lá jantar alguns domingos, ou eles vinham fazê-lo conosco. Jantar é pouco. Íamos sempre muito cedo, logo depois do almoço, para gozarmos o dia compridamente, e só nos separávamos às nove, dez e onze horas, quando não podia ser mais.

Em contrapartida à exuberância da década de 1980, vemos na de 1990 a diminuição do consumo. No período pós-colapso da bolsa em 1987, entre outras coisas, as pessoas passam a adotar um estilo mais contido, os chamados basics: peças de modelagem, como diz o nome, básicas em algumas variações de cores, confortáveis e práticas. Como os tops femininos de corte simples, t-shirts e blusas polo. Entram na história da moda como um minimalismo. 
"Less is more" é o lema. No final da década de 1990 e início dos anos 2000, não há na moda grandes novidades, os basics ainda são considerados confortáveis, práticos e materializam seus conceitos em tecidos de alta tecnologia, que não precisam ser engomados, passados, "transpiram", protegem dos raios UV, dentre outras novidades.

Filme baseado no romance Dom Casmurro, 1899.

Direção: Moacyr Góes;

Elenco: Marcos Palmeira, Maria Fernanda Cândido, Bruno Garcia, Luciana Braga, Malu Galli, Walter Rosa e Leon Góes;

Disponível em: http://cinema10.com.br/filme/dom. Acesso em: 1 fev. 2017. 